\title{
Revisited COVID-19 Mortality and Recovery Rates: Are we Missing Recovery Time Period?
}

\author{
H. R. Bhapkar ${ }^{1}$ - Parikshit N. Mahalle ${ }^{2}$ Nilanjan Dey ${ }^{3} \cdot$ K. C. Santosh ${ }^{4}$ (I) \\ Received: 27 August 2020 / Accepted: 15 October 2020 / Published online: 25 October 2020 \\ (C) Springer Science+Business Media, LLC, part of Springer Nature 2020
}

How difficult time it is due to COVID-19 pandemic can be determined by its mortality and/or recovery rates. Predictive modeling can help us forecast how big the impact will be, especially for human lives? Prediction is one of the wellknown studies that is entirely relying on machine learning based data analytics tools and techniques. In this study, we revisit mathematical models to measure severity levels of a COVID-19 pandemic.

A pandemic is an epidemic occurring on a scale that spreads rapidly across the world. The World Health Organization (WHO) considers epidemic diseases are Chikungunya, Cholera, Crimean - Congo hemorrhagic fever, Ebola Virus disease, Hendra virus infection, Influenza, Lassa fever, Plague, COVID-19, SARS, etc. In 2014, the United States Centre for Disease Control and Prevention (CDC) announced an equivalent framework to the WHO's pandemic stages titled pandemic intervals framework [1-3], where two pre-pandemic and four pandemic intervals were reported. Investigation and

This article is part of the Topical Collection on Education \& Training

K. C. Santosh

santosh.kc@usd.edu

H. R. Bhapkar

haribhau.bhapkar@mituniversity.edu.in

Parikshit N. Mahalle

pnmahalle@sinhgad.edu

Nilanjan Dey

neelanjan.dey@gmail.com

1 MIT ADTU's, MIT School of Engineering, Pune, India

2 Department of Computer Engineering, STES'S Smt. Kashibai Navale College of Engineering, Pune, India

3 Department of Computer Science \& Engineering, JIS University, Kolkata, India

4 Department of Computer Science, University of South Dakota, Vermillion, SD 57069, USA recognition are pre-pandemic intervals. Initiation, acceleration of diseases, deceleration, and preparation are pandemic intervals. In a similar fashion, instead of using pandemic intervals, we take recovery time period into account. Recovery time period can be two days, a week, two weeks, a month, six months, a year or any finite number of days. For COVID-19, we consider an average recovery time period of 14 days [4].

In March 2020, Baud et al. [4] reported to take 14 days delay into account in order to compute right mortality rate during the COVID-19 pandemic. Their study suggested that the classical mortality rate undervalue the probable threat due to COVID-19 in symptomatic cases. Of all metrics, to measure an austerity of the COVID-19 pandemic, in addition to mortality rates, recovery rate is considered. Both, mortality and recovery rates are useful metrics only when recovery time period is considered. Practically, one cannot compute mortality and recovery rates without considering its recovery time period. Inspired from previous work [4], we revisit mathematical models for both mortality and recovery rates, where not recovered cases and recovery time period are discussed thoroughly with both synthetic and real datasets.

In the sequel, for any disease, mortality rate (MR) defines the probability of death, and can be expressed as, MR $=\frac{\mathrm{D}}{\mathrm{N}}$ $\times 100$, where $\mathrm{D}$ and $\mathrm{N}$ refer to total number of deaths and infected people, respectively. While computing the MR, we consider the total number of an infected people till date, which will superfluously increase the denominator and hence decreases the MR. Therefore, practically, it is observed that the classical mathematical equation (to compute MR) may deviate from what it should be, since it does not take recovery time period into account. This primarily motivates us to revisit classical mathematical models.

Since recovery time periods vary a lot from person to person (of course, demography dependent, as reported in WHO [5]), it is important to define an average recovery time period $\left(\mathrm{P}_{\text {avg }}\right)$ as follows: 
$\mathrm{P}_{\text {avg }}=\left\{\begin{array}{cc}0, & \text { if } \mathrm{RP} \approx 0, \infty \\ \text { Arithmetic Mean, } & \text { otherwise }\end{array}\right.$

where we do not practically consider recovery time period (RP) on the exact same day cases are tested positive and those who are not recovered for months/years.

While revisiting, since mortality rate changes over time during COVID-19 pandemic, we call it Progressive Mortality Rate (PMR). In general, for any case/pandemic, $\mathrm{C}$ with an average recovery time period of $\mathrm{P}_{a v g}$, PMR can be computed as,

$\mathrm{PMR}=\frac{\mathrm{D}_{\mathrm{c}}}{\mathrm{N}_{\mathrm{P}_{\text {avg }}}} \times 100$,

where $\mathrm{D}_{\mathrm{c}}$ denotes the total number of death cases due to $\mathrm{C}$ disease and $\mathrm{Np}_{a v g}$ refers to a total number of infections before average recovery time period $\mathrm{P}_{\text {avg }}$.

Similarly, Recovery Rate (RR) used to follow classical mathematical equation, $R R=\frac{R}{N} \times 100$, where $R$ refers to total number of recovered cases. As before, when recovery time period is taken into account, Progressive Recovery Rate $(\mathrm{PRR})$ is,

$\mathrm{PRR}=\frac{\mathrm{R}_{\mathrm{C}}}{\mathrm{N}_{\mathrm{P}_{\text {avg }}}} \times 100$,

where $R_{c}$ refers to total number of recovered cases till date.

As a result, it is observed that we have notable differences between classical and revisited (progressive) rates. With $\mathrm{N}_{\mathrm{P}_{\text {avg }} \text {, }}$, progressive rates, as compared to classical rates, vary a lot during the pandemic period. The primary reason behind that is, for any $i^{\text {th }}$ day, progressive rates are calculated by taking data from (i-14) ${ }^{t h}$ day plus those recovered and death cases into account, where for COVID-19, we consider $\mathrm{P}_{\text {avg }}=14$.
Further, classical and progressive rates meet each other at the end i.e., $(j+14)^{\text {th }}$ day, where no new case is tested after $\mathrm{j}^{\text {th }}$ day. This means that mortality rates can only be determined by taking next average recovery time period from the day no new case(s) is(are) tested.

In previous correspondences [4, 6-8], the 14 days delay has been well discussed. However, since we do not have complete COVID-19 pandemic scenario, it is not trivial to get the real estimates from their models even though they look conceptually correct. To avoid possible confusions, we build a synthetic data, where we consider the first day having COVID-19 positive cases to the end of COVID-19 pandemic (see Table 2 in Appendix). Using our synthetic data, Fig. 1 shows how differences can happen when we take recovery time period into account. On 14th day, PMR and PRR are computed. Both classical and progressive rates meet each other when no new case is tested positive. As a result, these rates can be determined after 14 days from the day when no new case is tested positive. Interestingly, both classical and mathematical models hold exact same value at the end.

Mathematically speaking, PMR and PRR are disjoint sets. In other words, the set $U$ is the union of PMR and PRR, and the percentage of the cases that are Not Recovered (NR) within $P_{a v g}$. As a result, the cardinality of $U$ is 100 . Since recovery time period varies from person to person and is based on the severity level of infection [16], NR can be either positive, negative or zero:

$\mathrm{NR}=\left\{\begin{array}{lr}\leq 0, & \text { if } \mathrm{RP} \leq \mathrm{P}_{a v g} \\ >0, & \text { otherwise. }\end{array}\right.$

As before, PMR, PRR, and NR are disjoint sub-sets. As mentioned earlier, since recovery time period can be less than, equal to and more than $\mathrm{P}_{\text {avg }}$, Progressive total (PT) can be computed as

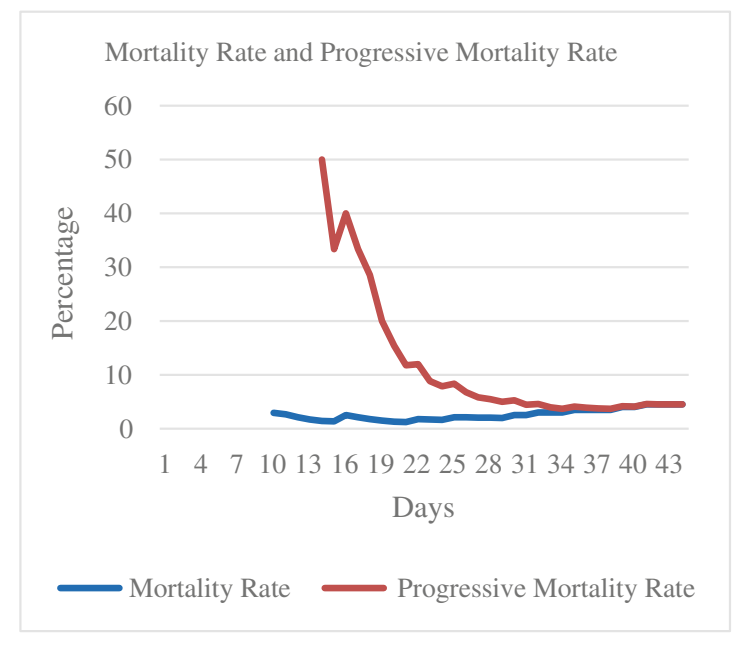

(a) Classical MR \& PMR

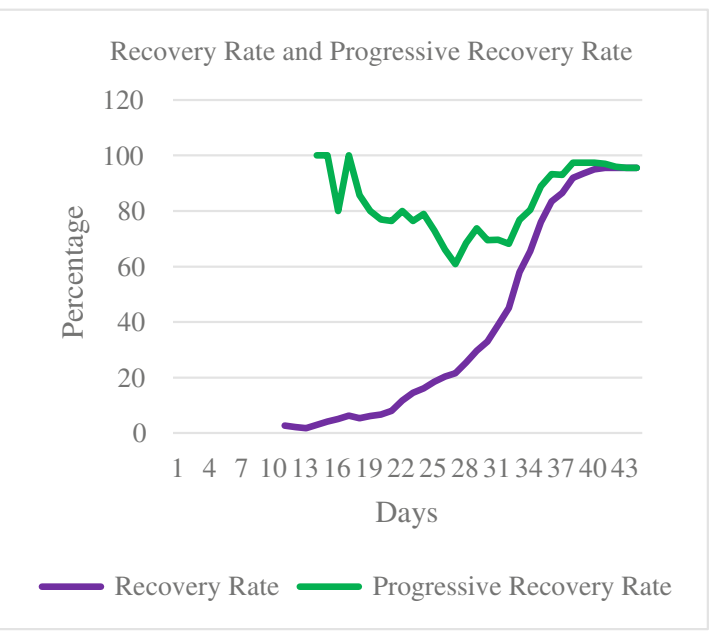

(b) Classical RR and PRR

Fig. 1 Relation between classical and progressive rates using synthetic data, where one can find a complete scenario from day 1 to day 30 , where no new case is tested positive after 30th day 
Fig. 2 Different values of Not Recovered (NR) cases in accordance with RP and $\mathrm{P}_{\mathrm{avg}}$ (data source: Table 2, appendix) in both PMR and PRR

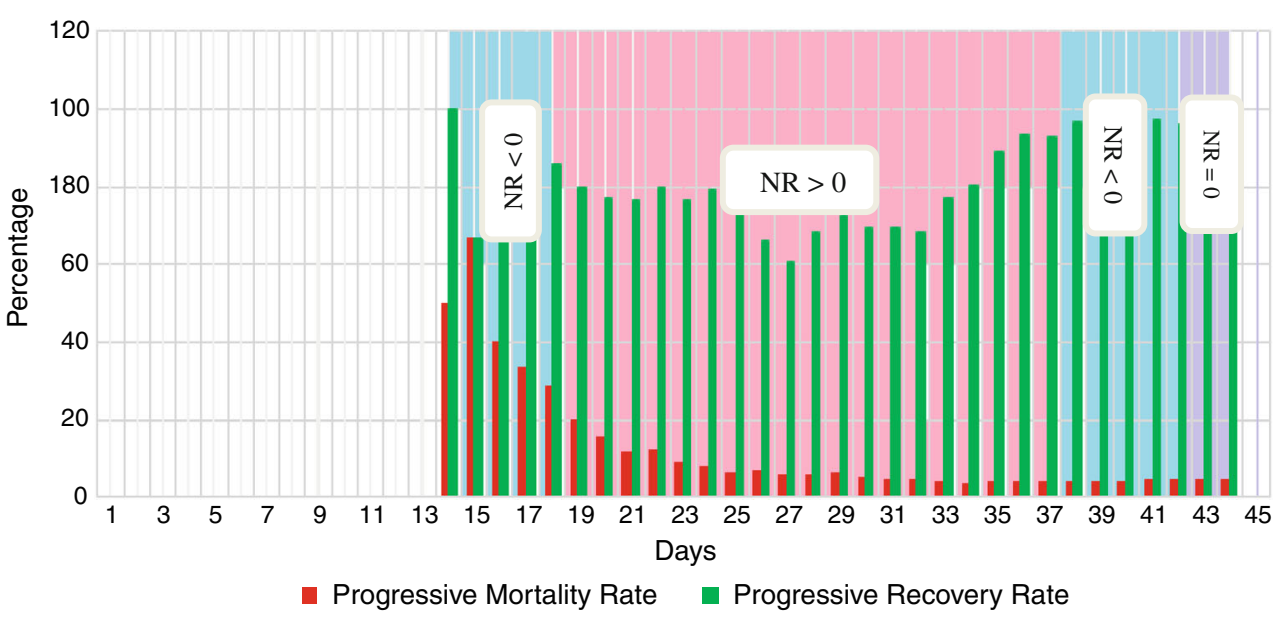

$\mathrm{PT}= \begin{cases}\leq 100, & \text { if } \mathrm{NR} \geq 0 \\ >100, & \text { otherwise },\end{cases}$

where PT changes with NR. On the whole, $\mathrm{PT}=\mathrm{PMR}+\mathrm{PRR}$.

The selection of $\mathrm{P}_{a v g}$ is crucial as it impacts progressive total, which is not the case when we compute classical MR and RR. In Fig. 2, using synthetic data (like in Fig. 1), we have a complete understanding of PRM and PRR from day 1 to day 44, where 30th day is the last day when no new COVID-19 positive is tested. Specifically, a) from day 14th to 18th and 38th to 42th, cases are recovered within $\mathrm{P}_{\text {avg }}$ and therefore, NR is negative; b) from day 19 th to 37 th, cases require more than 14 days to recover and therefore, NR is positive; and c) from 43rd to 45th, cases are recovered exactly on 14 days and therefore, NR is zero. In a nutshell, it is expected to have $\mathrm{NR} \leq 0$ for higher recovery rate. In other words, NR depends on PMR and PRR. With this note, PT reaches $100 \%$ when NR is zero. If $\mathrm{NR}<0, \mathrm{PT}$ crosses $100 \%$. This means that when PT crosses $100 \%$, infected cases are recovered in less than $\mathrm{P}_{\text {avg }}$.

For the exact same scenario ( $\mathrm{P}_{\text {avg }}=14$ days), considering the real-world data (see Table 1), one can see reasonable differences between classical and progressive mortality/recovery rates. In Table 1, countries are ranked in accordance with the increasing order of the mortality rate. Let us summarize the observations so one can understand how PMR, PRR, and PT rely on NR, where $\mathrm{P}_{\text {avg }}$ is crucial. Two cases can be summarized as follows:

a) $\mathrm{P}_{a v g} \leq 14$ : For Canada and Brazil, since PT is close to $100 \%$ (100.26\%, and $100.458 \%$, respectively), an average recovery time period is 14 days i.e., $\mathrm{P}_{\text {avg }} \approx 14$. In other words, all infected cases take 14 days (on an average) to get recovered. While for India, Mexico, and Japan, since PT is $109.29 \%, 108.39 \%$ and $103.9 \%$ respectively, which

Table 1 Computing MR, RR, PMR, PRR, and PT during the COVID-19 Pandemic

\begin{tabular}{|c|c|c|c|c|c|c|c|c|c|}
\hline Country & $\begin{array}{l}\text { Confirmed } \\
\text { cases (July 5) }\end{array}$ & $\begin{array}{l}\text { Confirmed } \\
\text { cases (July 18) }\end{array}$ & $\begin{array}{l}\text { Death } \\
\text { cases }\end{array}$ & $\begin{array}{l}\text { Recovered } \\
\text { cases }\end{array}$ & $\begin{array}{l}\text { Mortality } \\
\text { Rate } \\
\text { (classical) }\end{array}$ & $\begin{array}{l}\text { Recovery } \\
\text { Rate } \\
\text { (classical) }\end{array}$ & $\begin{array}{l}\text { Progressive } \\
\text { Mortality Rate } \\
\text { (PMR) }\end{array}$ & $\begin{array}{l}\text { Progressive } \\
\text { Recovery Rate } \\
\text { (PRR) }\end{array}$ & $\begin{array}{l}\text { Progressive } \\
\text { Total (PT) }\end{array}$ \\
\hline Singapore & 53,051 & 55,747 & 27 & 51,953 & 0.05 & 93.19 & 0.05 & 97.93 & 97.98 \\
\hline $\begin{array}{l}\text { New } \\
\text { Zeala- } \\
\text { nd }\end{array}$ & 1567 & 1631 & 22 & 1531 & 1.35 & 93.87 & 1.4 & 97.7 & 99.1 \\
\hline Russia & $8,54,641$ & $9,20,719$ & 15,653 & $7,31,444$ & 1.7 & 79.44 & 1.83 & 85.58 & 87.41 \\
\hline India & $18,03,695$ & $26,47,663$ & 50,921 & $19,19,842$ & 1.92 & 72.51 & 2.82 & 106.44 & 109.26 \\
\hline Japan & 40,099 & 56,074 & 1103 & 40,560 & 1.97 & 72.33 & 2.75 & 101.15 & 103.9 \\
\hline $\begin{array}{l}\text { United } \\
\text { State }\end{array}$ & $47,13,540$ & $54,03,213$ & $1,70,052$ & $18,33,067$ & 3.15 & 33.93 & 3.61 & 38.89 & 42.5 \\
\hline Brazil & $27,50,318$ & $33,40,197$ & $1,07,852$ & $26,55,017$ & 3.23 & 79.49 & 3.92 & 96.53 & 100.45 \\
\hline Germany & $2,12,111$ & $2,25,007$ & 9235 & $2,01,187$ & 4.1 & 89.41 & 4.35 & 94.85 & 99.2 \\
\hline China & 88,099 & 89,375 & 4703 & 83,200 & 5.26 & 93.09 & 5.34 & 94.44 & 99.78 \\
\hline Canada & $1,18,973$ & $1,24,004$ & 9074 & $1,10,202$ & 7.32 & 88.87 & 7.63 & 92.63 & 100.26 \\
\hline Mexico & $4,43,813$ & $5,22,162$ & 56,757 & $4,24,298$ & 10.87 & 81.26 & 12.79 & 95.6 & 108.39 \\
\hline
\end{tabular}


is more than $100 \%$, an average recovery time period is less than 14 days i.e., $\mathrm{P}_{\text {avg }}<14$.

b) $\mathrm{P}_{\text {avg }}>14$ : For remaining countries (from Table 1), since PT is less than $100 \%$, infected cases are taking more than 14 days to get recovered.

On the whole, in this study, considering recovery time period, we are not just limited to provide mathematical models for progressive mortality and recovery rates but also analyze the importance of recovery time period during the pandemic. We have provided our analyses by using both synthetic as well as real-world data.

At this point, it is important to note that even though the recovery time periods vary from one case/pandemic to other, the exact same mathematical models can be used to compute mortality and recovery rates.

\section{Compliance with ethical standards}

Conflict of interest Authors declared no conflict of interest.

Ethical approval This article does not contain any studies with human participants performed by any of the authors.

\section{Appendix}

In order to realize our revisited mathematical models for a complete COVID-19 pandemic scenario, we consider a city of 200 people. In our data, there are 2 COVID-19 positive cases on the first day, and 200 people get infected on 30th day. This means that after 30 days, no new cases are tested. Considering an average recovery time period of 14 days, we provide detailed information about classical and progressive rates for mortality and recovery rates (see Table below).

Table 2 Computing PMR, PRR, MR, and RR of COVID-19 Pandemic using synthetic data

\begin{tabular}{|c|c|c|c|c|c|c|c|c|c|}
\hline Days & $\begin{array}{l}\text { No. of } \\
\text { infections }\end{array}$ & $\begin{array}{l}\text { No. of } \\
\text { recovered } \\
\text { cases }\end{array}$ & $\begin{array}{l}\text { No. of } \\
\text { death } \\
\text { cases }\end{array}$ & $\begin{array}{l}\text { MortalityRate } \\
\text { (MR) } \\
\text { (classical) }\end{array}$ & $\begin{array}{l}\text { Progressive } \\
\text { Mortality Rate } \\
\text { (PMR) }\end{array}$ & $\begin{array}{l}\text { Recovery } \\
\text { Rate (RR) } \\
\text { (classical) }\end{array}$ & $\begin{array}{l}\text { ProgressiveRecovery } \\
\text { Rate (PRR) }\end{array}$ & $\begin{array}{l}\text { Progressive } \\
\text { Total (PT) }\end{array}$ & $\begin{array}{l}\% \text { of cases (not } \\
\text { recovered in P days, } \\
\text { where } P=14 \text { days) }\end{array}$ \\
\hline 1 & 2 & & & & & & & & \\
\hline 2 & 3 & & & & & & & & \\
\hline 3 & 5 & & & & & & & & \\
\hline 4 & 6 & & & & & & & & \\
\hline 5 & 7 & & & & & & & & \\
\hline 6 & 10 & & & & & & & & \\
\hline 7 & 13 & & & & & & & & \\
\hline 8 & 17 & & & & & & & & \\
\hline 9 & 25 & & & & & & & & \\
\hline 10 & 34 & & 1 & 2.94 & & & & & \\
\hline 11 & 38 & 1 & 1 & 2.63 & & 2.63 & & & \\
\hline 12 & 48 & 1 & 1 & 2.08 & & 2.08 & & & \\
\hline 13 & 59 & 1 & 1 & 1.69 & & 1.69 & & & \\
\hline 14 & 69 & 2 & 1 & 1.45 & 50.00 & 2.90 & 100.00 & 150.00 & -50.00 \\
\hline 15 & 73 & 3 & 1 & 1.37 & 33.33 & 4.11 & 100.00 & 133.33 & -33.33 \\
\hline 16 & 80 & 4 & 2 & 2.50 & 40.00 & 5.00 & 80.00 & 120.00 & -20.00 \\
\hline 17 & 95 & 6 & 2 & 2.11 & 33.33 & 6.32 & 100.00 & 133.33 & -33.33 \\
\hline 18 & 112 & 6 & 2 & 1.79 & 28.57 & 5.36 & 85.71 & 114.29 & -14.29 \\
\hline 19 & 132 & 8 & 2 & 1.52 & 20.00 & 6.06 & 80.00 & 100.00 & 0.00 \\
\hline 20 & 151 & 10 & 2 & 1.32 & 15.38 & 6.62 & 76.92 & 92.31 & 7.69 \\
\hline 21 & 163 & 13 & 2 & 1.23 & 11.76 & 7.98 & 76.47 & 88.24 & 11.76 \\
\hline 22 & 171 & 20 & 3 & 1.75 & 12.00 & 11.70 & 80.00 & 92.00 & 8.00 \\
\hline 23 & 179 & 26 & 3 & 1.68 & 8.82 & 14.53 & 76.47 & 85.29 & 14.71 \\
\hline 24 & 186 & 30 & 3 & 1.61 & 7.89 & 16.13 & 78.95 & 86.84 & 13.16 \\
\hline 25 & 189 & 35 & 4 & 2.12 & 8.33 & 18.52 & 72.92 & 81.25 & 18.75 \\
\hline 26 & 192 & 39 & 4 & 2.08 & 6.78 & 20.31 & 66.10 & 72.88 & 27.12 \\
\hline
\end{tabular}


Table 2 (continued)

\begin{tabular}{|c|c|c|c|c|c|c|c|c|c|}
\hline Days & $\begin{array}{l}\text { No. of } \\
\text { infections }\end{array}$ & $\begin{array}{l}\text { No. of } \\
\text { recovered } \\
\text { cases }\end{array}$ & $\begin{array}{l}\text { No. of } \\
\text { death } \\
\text { cases }\end{array}$ & $\begin{array}{l}\text { MortalityRate } \\
\text { (MR) } \\
\text { (classical) }\end{array}$ & $\begin{array}{l}\text { Progressive } \\
\text { Mortality Rate } \\
(\mathrm{PMR})\end{array}$ & $\begin{array}{l}\text { Recovery } \\
\text { Rate (RR) } \\
\text { (classical) }\end{array}$ & $\begin{array}{l}\text { ProgressiveRecovery } \\
\text { Rate (PRR) }\end{array}$ & $\begin{array}{l}\text { Progressive } \\
\text { Total (PT) }\end{array}$ & $\begin{array}{l}\% \text { of cases (not } \\
\text { recovered in P days, } \\
\text { where } P=14 \text { days) }\end{array}$ \\
\hline 27 & 195 & 42 & 4 & 2.05 & 5.80 & 21.54 & 60.87 & 66.67 & 33.33 \\
\hline 28 & 197 & 50 & 4 & 2.03 & 5.48 & 25.38 & 68.49 & 73.97 & 26.03 \\
\hline 29 & 199 & 59 & 4 & 2.01 & 5.00 & 29.65 & 73.75 & 78.75 & 21.25 \\
\hline 30 & 200 & 66 & 5 & 2.50 & 5.26 & 33.00 & 69.47 & 74.74 & 25.26 \\
\hline 31 & 200 & 78 & 5 & 2.50 & 4.46 & 39.00 & 69.64 & 74.11 & 25.89 \\
\hline 32 & 200 & 90 & 6 & 3.00 & 4.55 & 45.00 & 68.18 & 72.73 & 27.27 \\
\hline 33 & 200 & 116 & 6 & 3.00 & 3.97 & 58.00 & 76.82 & 80.79 & 19.21 \\
\hline 34 & 200 & 131 & 6 & 3.00 & 3.68 & 65.50 & 80.37 & 84.05 & 15.95 \\
\hline 35 & 200 & 152 & 7 & 3.50 & 4.09 & 76.00 & 88.89 & 92.98 & 7.02 \\
\hline 36 & 200 & 167 & 7 & 3.50 & 3.91 & 83.50 & 93.30 & 97.21 & 2.79 \\
\hline 37 & 200 & 173 & 7 & 3.50 & 3.76 & 86.50 & 93.01 & 96.77 & 3.23 \\
\hline 38 & 200 & 184 & 7 & 3.50 & 3.70 & 92.00 & 97.35 & 101.06 & -1.06 \\
\hline 39 & 200 & 187 & 8 & 4.00 & 4.17 & 93.50 & 97.40 & 101.56 & -1.56 \\
\hline 40 & 200 & 190 & 8 & 4.00 & 4.10 & 95.00 & 97.44 & 101.54 & -1.54 \\
\hline 41 & 200 & 191 & 9 & 4.50 & 4.57 & 95.50 & 96.95 & 101.52 & -1.52 \\
\hline 42 & 200 & 191 & 9 & 4.50 & 4.52 & 95.50 & 95.98 & 100.50 & -0.50 \\
\hline 43 & 200 & 191 & 9 & 4.50 & 4.50 & 95.50 & 95.50 & 100.00 & 0.00 \\
\hline 44 & 200 & 191 & 9 & 4.50 & 4.50 & 95.50 & 95.50 & 100.00 & 0.00 \\
\hline
\end{tabular}

Index:
a) $\mathrm{MR}=\frac{\mathrm{D}}{\mathrm{N}} \times 100$
(b) $\mathrm{PMR}=\underline{\mathrm{D}_{\mathrm{C}}} \mathrm{N}_{\mathrm{P}_{\text {avg }}} \times 100$;
c) $R R=\frac{R}{N} \times 100$;
d) $P R R=\frac{R_{C}}{N_{P_{a v g}}} \times 100$;
e) PT $=$ PMR + PRR; and
f) $\mathrm{NR}=100-\mathrm{PT}$.

\section{References}

1. Viboud, C., Simonsen, L., Fuentes, R., Flores, J., Miller, M. A., \& Chowell, G. (2016). Global mortality impact of the 1957-1959 influenza pandemic. The Journal of infectious diseases, 213(5), 738745 .

2. Luk, J., Gross, P., \& Thompson, W. W. (2001). Observations on mortality during the 1918 influenza pandemic. Clinical Infectious Diseases, 33(8), 1375-1378.

3. Murray, C. J., Lopez, A. D., Chin, B., Feehan, D., \& Hill, K. H. (2006). Estimation of potential global pandemic influenza mortality on the basis of vital registry data from the 1918-20 pandemic: a quantitative analysis. The Lancet, 368(9554), 2211-2218.

4. David Baud, Xiaolona Qi, Karin Nielsen-Saines etc Real estimates of mortality following COVID 19 infection, correspondence, Lancet, volume 20 July 2020,773
5. WHO Director-General's opening remarks at the media briefing on COVID-19 - 24 Feb. 2020, URL: https://www.who.int/dg/speeches/ detail/who-director-general-s-opening-remarks-at-the-mediabriefing-on-covid-19\%2D\%2D-24-february-2020.

6. David Dongkyung Kim, Akash Goel, Real estimates of mortality following COVID 19 infection, correspondence, Lancet, volume 20 July 2020, 773-774.

7. Piotr Spychalski, Agata Błażyńska-Spychalska, Jarek Kobielal Real estimates of mortality following COVID 19 infection, correspondence, Lancet, volume 20 July 2020, 774-775.

8. Marc Lipsitch, Real estimates of mortality following COVID 19 infection, correspondence, Lancet, volume 20 July 2020, 775.

Publisher's Note Springer Nature remains neutral with regard to jurisdictional claims in published maps and institutional affiliations. 